\title{
ON A NONLINEAR WAVE EQUATION IN UNBOUNDED DOMAINS
}

\author{
CARLOS FREDERICO VASCONCELLOS \\ Instituto de Matemática \\ Universidade Federal do Rio de Janeiro \\ P.O. Box 68530 CEP 21944, Rio de Janeiro, RJ \\ Brazil
}

(Received October 16, 1986)

ABSTRACT. We study existence and uniqueness of the nonlinear wave equation

$$
\frac{\partial^{2} u}{\partial t^{2}}+M\left(x, \int|\nabla u(x, t)|^{2} d x+\int|u(x, t)|^{2} d x\right)(-\Delta u+u)=0
$$

in unbounded domains. The above model describes nonlinear wave phenomenon in non-homogeneous media. Our techniques involve fined point arguments combined with the energy method.

KEY WORDS AND PHR/SES. Nonlinear equation, unbounded domain, energy method, fixed point theorems.

1980 AMS SUBJECT CLASSIFICATION CODE. $35 \mathrm{L7O}$.

\section{INTRODUCTION}

In this paper we prove the existence and uniqueness of a local solution for the following problem:

$$
\mid \begin{aligned}
& \frac{\partial^{2} u}{\partial t^{2}}+M\left(x,\|u(t)\|^{2}\right) A u=0 \\
& u(x, 0)=u_{0} \quad u_{t}(x, 0)=u_{1}(x)
\end{aligned}
$$

where $M: \mathbb{R}^{n} \times \mathbb{R} \rightarrow \mathbb{R}$,

$$
\|u(t)\|^{2}=\sum_{j=1}^{n} \int_{\mathbb{R}^{n}}\left|\frac{\partial u}{\partial x_{j}}(x, t)\right|^{2} d x+\int_{\mathbb{R}^{n}}|u(x, t)|^{2} d x, \quad \forall t \geq 0
$$

and

$$
A u=-\Delta u+u=-\sum_{j=1}^{n} \frac{\partial^{2} u}{\partial x_{i}^{2}}+u
$$

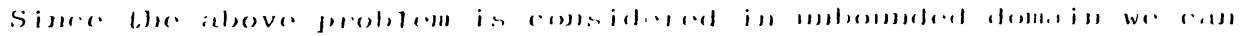

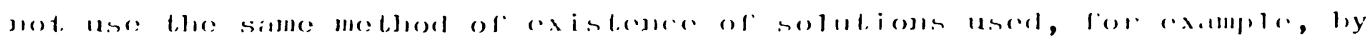
P.ll. Rivera ([1]), in which he studied llle froblem (1.1) wholl x russ in a bounded open subset of $R^{\text {nl }}$. He found a weak local solutionfor the problem using Galerkin method and the discrete spectrum of the Ialphatalu operatior in bounded domains. 
In the other hand, since that the mappingr $M$ depends explicity on $x$ we can not use Fourier transform as was done, for cxample, by. G.P. Menzala ([2]) in which he studied the problem $(1.1)$ when $M(\lambda, \lambda)=M_{0}(\lambda)$, that is when the mapping $M$ is independent of $x$.

Our assumptions about the mapping $M$ are described below.

There exist runctions $\varphi, \psi \in w^{l, \infty}\left(\mathbb{R}^{n}\right)$ and $m_{0}>0$ such that $\varphi(x) \geq$ $\geq m_{0}>0$ a.e. in $\mathbb{R}^{n}, \psi(x) \geq 0$ a.e. in $\mathbb{R}^{n}$ and $M(x, \lambda)=\varphi(x)+$ $+r(\lambda) \psi(x), \quad(x, \lambda) \in \mathbb{R}^{n} x \mathbb{R}$ where $f: \mathbb{R} \rightarrow \mathbb{R}$ is continuously dirrerentiable with $r(\lambda) \geq 0$ for $\lambda \geq 0$.

Here $W^{1, \infty}\left(\mathbb{R}^{n}\right)=\left\{\varphi \leqslant L^{\infty}\left(\mathbb{R}^{n}\right): \frac{\partial \varphi}{\partial x} \in L^{\infty}\left(\mathbb{R}^{n}\right), \quad j=1, \ldots, n\right\}$. We also consider the usual Sobolev space $H^{1}\left(\mathbf{R}^{n}\right)$ with the norm

$$
\|u\|^{2}=\sum_{j=1}^{n} \int_{\mathbb{R}^{n}}\left|\frac{\partial u}{\partial x_{j}}(x)\right|^{2} d x+\int_{\mathbb{R}^{n}}|u(x)|^{2} d x
$$

Our main result in this paper will be:

There exists a unique local solution for problem (1.1) with the following properties:

There exists $T_{2}>0$ and a function $u: \mathbb{R}^{n} \times\left[0, T_{2}\right] \rightarrow \mathbb{R}$ which belongs to $C_{w}^{2}\left(\left[0, T_{2}\right] ; L^{2}\left(\mathbb{R}^{n}\right)\right) \cap C^{1}\left(\left[O, T_{2}\right] ; L^{2}\left(\mathbb{R}^{n}\right)\right) \cap$ $\cap \mathrm{C}\left(\left[0, \mathrm{~T}_{2}\right] ; \mathrm{H}^{1}\left(\mathbb{R}^{\mathrm{n}}\right)\right)$.

For each $t<T_{2} u(\cdot, t) \in H^{2}\left(\mathbb{R}^{n}\right)$ and $\frac{\partial u}{\partial t}(\cdot, t) \in H^{l}\left(\mathbb{R}^{n}\right)$.

Here $C_{\omega}^{2}\left(\left[0, T_{2}\right] ; L^{2}\left(R^{n}\right)\right)=\left\{u:\left[0, T_{2}\right] \rightarrow L^{2}\left(\mathbb{R}^{n}\right): t \mapsto(u(t) \mid v)\right.$ is twice continuously differentiable in $\left.\left[0, T_{2}\right], \forall v \in L^{2}\left(R^{n}\right)\right\}$ where $(\cdot \mid \cdot)$ denotes the usual inner product in $L^{2}\left(\mathbb{R}^{n}\right)$. We also denote by $H^{2}\left(\mathbb{R}^{n}\right)$ the usual Sobolev space of order two.

The basic idea in order to obtain our result will be to use fixed point arguments together with the energy method in appropriate Banach spaces.

It is important to observe that our main result holds also in any open subset of $\mathbb{R}^{\mathbf{n}}$.

Before concluding this introduction we would like to make a few comments on the literature. J.L. Lions ([3]) considered the problem:

$$
\mid \begin{aligned}
& \frac{\partial^{2} u}{\partial t^{2}}-M\left(\int_{\Omega}|\nabla u|^{2} d x\right) \Delta u=0 \quad \Omega \times(0, T) \\
& u(x, 0)=u_{0}(x), \quad u_{t}(x, 0)=u_{1}(x)
\end{aligned}
$$

where $M(\lambda) \geq m_{0}>0$ and $\Omega$ denotes a bounded open subset of $\mathbb{R}^{\mathrm{n}}$.

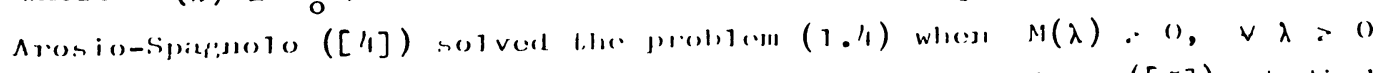

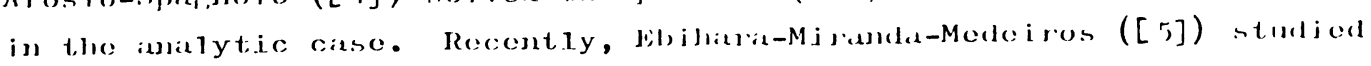
problem $(1.4)$ when $M(\lambda) \geq 0, \forall \lambda \geq 0$ for more general cascs. Others authors like Andrade $([6])$, Ball $([7])$, Bernstein ([8]), Dickey $([9])$, Greenbere-llu $([10])$, Medeiros $([11])$, Menzala ([12]), Nishida ([13]), Nislihara $([14])$, Pohoxaev $([15])$, Rivera $([16])$, Ribeiro $([17])$ und Yamada $([18,19])$ also studied related problems. 


\section{2. $\Lambda$ PRELIMINARY RESULT}

In this section we prove the existence and uniqueness of a solution of the following "linearized" problem: Let $T>0$. Let $v \in C^{1}\left([0, T] ; H^{1}\left(\mathbb{R}^{n}\right)\right)$

$$
\mid \begin{aligned}
& \frac{\partial^{2} u}{\partial t^{2}}+M\left(x,\|v(t)\|^{2}\right) A u=0 \text { in } \mathbb{R}^{n} \times(0, T] \\
& u(x, 0)=u_{0}(x) \quad u_{t}(x, 0)=u_{1}(x)
\end{aligned}
$$

From now on we shall denote by $H$ the usual space $L^{2}\left(\mathbb{R}^{n}\right)$ in which we consider the norm $|u|^{2}=\int_{\mathbb{R}^{n}}|u(x)|^{2} \mathrm{dx}$ and inner product (u|v). Let us consider the linear operator $A: D(A) \subset H \rightarrow H$ defined by $A u=-\Delta u+u$, with $D(A)=H^{2}\left(\mathbb{R}^{n}\right)$. Clearly $A$ is self-adjoint and satisfies:

$$
(A u \mid u) \geq|u|^{2}, \quad u \in D(A) \text {. }
$$

All functions we consider in this paper will be real valued. The square root of $A$, denoted by $A^{1 / 2}$ has domain $V=D\left(A^{1 / 2}\right)=H^{1}\left(\mathbb{R}^{n}\right)$. The inner product in $\mathrm{V}$ is defined by:

$$
[u \mid v]=\left(A^{1 / 2} u \mid A^{1 / 2} v\right)=\sum_{j=1}^{n} \int_{\mathbb{R}^{n}} \frac{\partial u}{\partial x_{j}} \frac{\partial v}{\partial x_{j}} d x+\int_{\mathbb{R}^{n}} u(x) v(x) d x
$$

with norm $\|\cdot\|$ defined in $\S 1$.

For each $\lambda \in \mathbb{R}$ we define $B(\lambda): H \rightarrow H$ by $B(\lambda) u=M(\cdot, \lambda) u$. Because of our assumptions on $M(x, \lambda)$ the operator $B(\lambda)$ has the following properties:

For each $\lambda \in \mathbb{R}, \quad B(\lambda)$ is a linear boundedsymmetric operator on $\mathrm{H}$.

For each $\lambda \geq 0(B(\lambda) u \mid u) \geq m_{0}|u|^{2}, \quad u \in H$

For each $\lambda \geq 0 \quad B(\lambda): V \rightarrow V$ is a linear continuous bijective operator

$\forall \mathrm{T}>0$ 过 $\alpha_{\mathrm{T}}>0$ such that $\left\|\mathrm{B}\left(\lambda_{1}\right)-\mathrm{B}\left(\lambda_{2}\right)\right\|_{\mathcal{L}(\mathrm{V})} \leq \alpha_{\mathrm{T}}\left|\lambda_{1}-\lambda_{2}\right|$ if $\left|\lambda_{1}\right|,\left|\lambda_{2}\right| \leq T$. Here $\mathcal{L}(V)$ is the space of 1 inear continuous operators on $\mathrm{V}$

$\forall \mathrm{T}>\mathrm{O}$ \& $\beta_{\mathrm{T}}>\mathrm{O}$ such that if $(\mathrm{u}, \mathrm{v}) \in \mathrm{D}(\mathrm{A}) \times \mathrm{V}$ and $|\lambda| \leq \mathrm{T}$ $\left|(B(\lambda) A u \mid v)-\left(B(\lambda) A^{1 / 2} u \mid A^{1 / 2} v\right)\right| \leq \beta_{T}\|u\||v|$

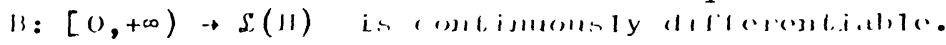

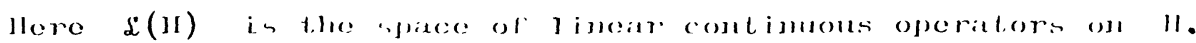
JEMMA 1. Jot $\mathrm{v}$ holosirime to $\mathrm{C}^{1}(\mathrm{ar} ; \mathrm{V})$, thon $\forall t \in \mathbb{R} \quad N(t)=\Lambda^{1 / 2} B\left(\|v(t)\|^{2}\right) \Lambda^{1 / 2}$ is a self arjoint operator in $\|$ with lomian $\mathrm{D}(\mathrm{N}(\mathrm{t}))=\mathrm{D}(\Lambda), \quad \forall t \in \mathbb{R}$. $(N(t) u \mid u) \geq m_{0}|u|^{2} \quad \forall t \in \mathbb{R}$ and $\forall u \in D(A)$

$\forall \mathrm{T}>\mathrm{O}$ there is $\mathrm{m}_{\mathrm{T}}$ such that

$\left\|N(t) N^{-1}(0)-N(S) N^{-1}(0)\right\|_{\mathcal{L}(H)} \leq m_{T}|t-s|$

whenever $|t|,|s| \leq T$. 
PROOF: By (2.4) we can show that $D(N(t))=D(A), \forall t \in \mathbb{R}$ and that the image of $N(t)$ is $H$. Hence since $A^{1 / 2}$ and $B\left(\|v(t)\|^{2}\right)$ are symmetric we obtain $(2.8)$.

In the other hand if $u \in D(A)$ we obtain by (2.1) and (2.3) that $(N(t) u \mid u)=\left(B\left(\|v(t)\|^{2}\right) A^{1 / 2} u \mid A^{1 / 2} u\right) \geq m_{0}\left|A^{1 / 2} u\right|^{2} \geq m_{0}|u|^{2}$ therefore (2.9) follows.

To prove (2.10) we observe by $(2.8)$ and the closed graph theorem, that $N(t)[N(0)]^{-1} \in \mathcal{L}(\mathrm{H})$.

We consider $u \in H$ and $T>0$, then by $(2.5)$ we obtain, $\left|N(t)[N(0)]^{-1} u-N(s)[N(0)]^{-1} u\right| \leq \alpha_{T} \|\left[B\left(\|v(0)\|^{2}\right]^{-1} \|_{\delta(v)}|u||t-s|\right.$

$|t|,|s| \leq T$ which proves (2.10).

PROPOSITION 1. Let $u_{0} \in H^{3}\left(\mathbb{R}^{n}\right)=D\left(A^{3 / 2}\right), u_{1} \in H^{2}\left(\mathbb{R}^{n}\right)$ and $v \in C^{1}(\mathbb{R} ; v)$.

Then there is a unique function $u: \mathbb{R} \rightarrow H^{3}\left(\mathbb{R}^{n}\right)$ such that:

$u \in C^{2}(\mathbb{R} ; V) \cap C^{1}(\mathbb{R} ; D(A))$

$\mid \begin{aligned} & u^{\prime \prime}+B\left(\|v(t)\|^{2}\right) A u(t)=0 \text { in } \quad V \times \mathbb{R} \\ & u(0)=u_{0} \quad u^{\prime}(0)=u_{1}\end{aligned}$

PROOF: By Lemma 1 and a result due to J. Goldstein (see Theorem 2.2. in [20]) there is a unique function $w: \mathbb{R} \rightarrow H^{2}\left(\mathbb{R}^{n}\right)$ such that

$w \in C^{2}(\mathbb{R} ; H) \cap C^{1}(\mathbb{R} ; V)$

$\mid \begin{array}{ll}w^{\prime \prime}+N(t) w(t)=0 & \text { in } H \times \mathbb{R} \\ w(0)=A^{1 / 2} u_{0} & w^{\prime}(0)=A^{1 / 2} u_{1}\end{array}$

Let us consider $u(t)=A^{-1 / 2} w(t)$ for $t \in \mathbb{R}$ then $u: \mathbb{R} \rightarrow H^{3}\left(\mathbb{R}^{n}\right)$ satisfies (2.11) and (2.12).

Therefore it follows that $u$ is the unique solution of (2.12) which satisfies (2.11).

PROPOSITION 2. Let $T$ be a positive real number. Then given $v \in C^{1}(0, T ; v), \quad u_{0} \in H^{3}\left(\mathbb{R}^{n}\right)=D\left(A^{3 / 2}\right)$ and $u_{1} \in H^{2}\left(\mathbb{R}^{n}\right)$. There is a unique function $u=u(v):[0, T] \rightarrow H^{3}\left(\mathbb{R}^{n}\right)$ such that:

$u \in c^{2}(0, T ; v) \cap C^{1}(0, T ; D(A))$

$\mid \begin{array}{ll}u \prime+11(\|v(1)\|:) \wedge u(1)=0 \\ u(0)=u_{0} & v^{\prime}(0)=u_{1}\end{array}$

Plroor: We define

$$
w(t)=\left\{\begin{array}{llr}
v(t) & \text { if } & 0 \leq t \leq T \\
v^{\prime}(T)(t-T)+v(t) & \text { if } & t>T \\
v^{\prime}(0) t+v(0) & \text { if } & t<0
\end{array}\right.
$$

$w \in C^{1}(\mathbb{R} ; v)$ and hence there is $u=u(w): R \rightarrow H$ which satisfies the Proposition 1 , in particular $u$ satisfies (2.15) and (2.16), with $\mathrm{u}:[\mathrm{O}, \mathrm{T}] \rightarrow \mathrm{H}^{3}\left(\mathbb{R}^{\mathrm{n}}\right)$.

Remains to prove the uniqueness. Suppose that we have another solution $z$ of $(2.16)$ which satisfies (2.15). 
Then $\sigma(t)=u(t)-z(t)$ satisfies

$\mid \begin{aligned} & \sigma^{\prime \prime}(t)+B\left(\|v(t)\|^{2}\right) A \sigma=0 \quad \text { in } \quad v \times[0, T] \\ & \sigma(0)=0 \quad \sigma^{\prime}(0)=0\end{aligned}$

We consider $\tau(t)=\frac{1}{2}\left\{\left|\sigma^{\prime}(t)\right|^{2}+\left(B\left(\|v(t)\|^{2}\right) A^{1 / 2} \sigma \mid A^{1 / 2} \sigma\right)\right\}$ then by (2.17) we obtain that

$$
\begin{aligned}
\tau^{\prime}(t)= & -\left(B\left(\|v(t)\|^{2}\right) A \sigma \mid \sigma^{\prime}\right)+\left(B\left(\|v(t)\|^{2}\right) A^{1 / 2} \sigma \mid A^{1 / 2} \sigma^{\prime}\right)+ \\
& +\left[v(t) \mid v^{\prime}(t)\right]\left(B^{\prime}\left(\|v(t)\|^{2}\right) A^{1 / 2} \sigma \mid A^{1 / 2} \sigma\right) .
\end{aligned}
$$

Hence by $(2.6)$ and $(2.7)$

$$
\tau^{\prime}(t) \leq \frac{\beta_{T}}{2}\left(\|\sigma(t)\|^{2}+\left|\sigma^{\prime}(t)\right|^{2}\right)+C_{T}\|\sigma(t)\|^{2}
$$

where

$$
\mathrm{C}_{\mathrm{T}}=\sup _{\mathrm{O} \leq \mathrm{t} \leq \mathrm{T}}\left(\left\|\mathrm{B}^{\prime}\left(\|v(t)\|^{2}\right)\right\|_{\mathcal{L}(\mathrm{H})}\|\mathrm{v}(\mathrm{t})\|\left\|\mathrm{v}^{\prime}(t)\right\|\right) .
$$

Now, using $(2.3)$ we obtain that there exists $\eta_{T}>0$ such that:

$$
\tau^{\prime}(t) \leq \eta_{T} \tau(t), \quad t \in(0, T] \text {. }
$$

Hence, since $\tau(0)=0$, it follows that $\tau(t)=0, \forall t \in[0, T]$ which proves the Proposition 2.

COROLLARY 1. Let $v \in V^{1}\left(0, T ; V\left(\mathbb{R}^{n}\right)\right), u_{0} \in H^{3}\left(\mathbb{R}^{n}\right)$ and $u_{1} \in H^{2}\left(\mathbb{R}^{n}\right)$. Then there is a unique $u:[0, T] \rightarrow H^{3}\left(\mathbb{R}^{n}\right)$ such that:

$u \in C^{2}\left([0, T] ; H^{1}\left(\mathbb{R}^{n}\right)\right) \cap C^{1}\left([0, T] ; H^{2}\left(\mathbb{R}^{n}\right)\right)$ and satisfies $(2.0)$.

\section{SOLUTION OF PROBLEM (1.1)}

We consider $T>0$ and we denote by $X_{T}=\{u:[0, T] \rightarrow H:$

$u \in C^{1}(O, T ; V) \cap C(O, T ; D(A)\}$. Clearly $X_{T}$ is a Banach space with the norm $\|u\|_{X_{T}}=\sup _{0 \leq t \leq T}\left\{\left\|u^{\prime}(t)\right\|+|A u(t)|\right\}$. Now, we consider

$u_{0} \in H^{3}\left(\mathbb{R}^{n}\right)=D\left(A^{3 / 2}\right)$ and $u_{1} \in D(A)=H^{2}\left(\mathbb{R}^{n}\right)$. We observe that given $\mathrm{v} \in \mathrm{X}_{\mathrm{T}}$ there is a unique $\mathrm{u}=\mathrm{S}(\mathrm{v}) \in \mathrm{X}_{\mathrm{T}}$ which satisfies (2.15) and

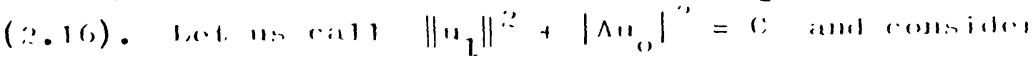

$\mathrm{E}_{\mathrm{T}, \mathrm{C}}=\left\{\mathrm{v}: \mathrm{x}_{\mathrm{T}}:\|\mathrm{v}(0)\|: ? \mathrm{c}\right\}$.

Limp 2. There are $r=r(c)>0$ ind $T_{0}=T_{0}(c)>0$ such liniat ir $\mathrm{v} \in \mathrm{E}_{\mathrm{T}_{\mathrm{O}}, \mathrm{C}}$ ind $\|\mathrm{v}\|_{\mathrm{X}_{\mathrm{T}_{\mathrm{O}}}} \leqslant \mathrm{r}$, then $\|\mathrm{s}(\mathrm{v})\|_{\mathrm{X}_{\mathrm{T}_{\mathrm{o}}}}^{\circ} \leqslant \mathrm{r}$.

PROOF: We consider $\mathrm{T}>0$ and $u=s(v)$ where $v \in X_{T}$ and we derine $z(t)=\frac{1}{2}\left\{\left\|u^{\prime}(t)\right\|^{2}+\left(B\left(\|v(t)\|^{2}\right) A u \mid \Lambda u\right)\right\}$. Thus, since u satisficen (2.16) we obtain that $z^{\prime}(t)=\left[v^{\prime}(t) \mid v(t)\right]\left(B^{\prime}\left(\|v(t)\|^{2}\right) A u \mid \Lambda u\right)$. Thererore, by $(2.3)$

$z^{\prime}(t) \leq \frac{2}{m_{0}}\|v\|_{X_{T}}^{2}\left\|B^{\prime}\left(\|v(t)\|^{2}\right)\right\|_{\mathcal{L}(I I)} z(t)$.

Let

$$
r=\sqrt{\frac{4 \mathrm{C}\left(1+\left\|\mathrm{B}\left(\|\mathrm{v}(\mathrm{O})\|^{2}\right)\right\|_{\mathcal{L}(\mathrm{H})}\right.}{\min \left(1, \mathrm{~m}_{\mathrm{o}}\right)}} .
$$

Therefore if $\|v\|_{X_{T}} \leq r$ then $\left\|B^{\prime}(\|v(t)\|)\right\| \leq Y_{c}, \quad 0 \leq t \leq T$. Thus, by (3.1) we obtain that:

$z(t) \leq z(0) \exp \left(\frac{2}{m_{0}} r^{2} \gamma_{c} t\right), \quad 0 \leq t \leq T$. 
We choose $T_{0}=\min \{T, \mu\}$, where $\mu=\frac{m_{o}}{2 r^{2} Y_{c}}-10 g 2$ then $\log$ cach $0 \leq t \leq T_{0}$, we conclude thit

$$
z(t) \leq 2 z(0) \leq C\left(1+\left\|B\left(\|v(0)\|^{2}\right)\right\|_{\mathcal{L}(H)}\right)
$$

and so, by $(2.3)$

$$
\left(\left\|u^{\prime}(t)\right\|+|A u(t)|\right)^{2} \leq r^{2}, \text { for } 0 \leq t \leq T_{0} \text {. }
$$

This completes the proof of Lemma 2 .

Now, we define the space $Y_{T}=\{u:[0, T] \rightarrow H: u \in C(0, T ; V) \cap$ $\left.\cap \mathrm{C}^{1}(\mathrm{O}, \mathrm{T} ; \mathrm{H})\right\}$ with the norm:

$$
\|u\|_{Y_{T}}=\sup _{O \leq t \leq T}\left\{\|u(t)\|+\left|u^{\prime}(t)\right|\right\}
$$

Clearly $Y_{T}$ is a Banach space.

LEMMA 3. We consider $r$ and $T_{0}>0$ as in Lemma 2. Then there are $0<T_{1} \leqslant T_{0}$ and $0<\theta<1$ such that

$\|S(u)-S(v)\|_{Y_{T_{1}}} s \theta\|u-v\|_{Y_{T_{1}}}$ for every $u$ and $v$ in $E_{T_{1}, C}$

with $\|u\|_{\mathrm{X}_{\mathrm{T}_{1}}} \leq \mathrm{r}$ and $\|v\|_{\mathrm{X}_{\mathrm{T}_{1}}} \leq \mathrm{r}$.

PROOF: Let us consider $u$ and $v$ in $E_{T_{0}, C}$ Then $\sigma(t)=$ $=s(u)(t)-s(v)(t) \quad$ satisfies:

$$
\mid \begin{aligned}
& \sigma^{\prime \prime}(t)+B\left(\|u(t)\|^{2}\right) A \sigma+\left[B\left(\|u(t)\|^{2}\right)-B\left(\|v(t)\|^{2}\right)\right] A S(v)=0 \\
& \sigma(0)=0=\sigma^{\prime}(0)
\end{aligned}
$$

If we define

$$
y(t)=\frac{1}{2}\left\{\left|\sigma^{\prime}(t)\right|^{2}+\left(B\left(\|u(t)\|^{2}\right) A^{1 / 2} \sigma \mid A^{1 / 2} \sigma\right)\right\}
$$

by $(2.6)$ and $(3.4)$, then we obtain that:

$$
\begin{aligned}
& y^{\prime}(1) \cdot B_{\text {, }}\|\sigma(1)\|\left|\sigma^{\prime}(1)\right|+ \\
& +\left\|\mathrm{u}\left(\|\mathrm{u}(\mathrm{t})\|^{2 \prime}\right)-\mathrm{3}\left(\|\mathrm{v}(\mathrm{l})\|^{\prime 2}\right)\right\|_{\mathcal{S}(\mathrm{u})}|\wedge \mathrm{s}(\mathrm{v})|\left|\sigma^{\prime}(\mathrm{l})\right|+ \\
& +\left\|u^{\prime}(t)\right\| \mid \Lambda u(t)\|\| 3^{\prime}\left(\|u(t)\|^{2}\right)\left\|_{\mathcal{L}(I I)}\right\| \sigma(t) \|^{2} \text {. }
\end{aligned}
$$

I. $\|u\|_{X_{T_{0}}} \leq r$ and $\|v\|_{X_{T_{0}}} \leq r$, then by $(2.3),(2.5)$ and Lemmit 2 aloove we olstain that

$y^{\prime}(t) \leq\left(\frac{2}{\sqrt{m_{0}}} \beta_{T_{0}}+\frac{2}{m_{0}} \gamma_{c} r^{2}\right) y(t)+2 \alpha_{T_{0}} r^{2}\|u-v\|_{Y_{T_{0}}}\|\sigma\|_{Y_{T_{0}}}$.

Let us consider $\Gamma=\frac{1}{\sqrt{m_{0}}} \beta_{T_{0}}+\frac{1}{m_{0}} \gamma_{c} r^{2}$. Then, since that $y(0)=0$, we obtain by $(3.5)$ that

$y(1) \leq \frac{\alpha_{T_{0}} r^{2}}{\Gamma}\left(e^{2 \Gamma t}-1\right)\|u-v\|_{Y_{T_{0}}}\|\sigma\|_{Y_{T_{0}}}, \quad 0 \leq t \leq T_{0}$.

Now, we choose $T_{1}<\min \left\{T_{0}, \frac{1}{2 \Gamma} \log \left(\frac{\min \left(1, m_{0}\right) \Gamma}{4 \alpha_{T}^{2} r^{2}}+1\right)\right\}$.

If we repeat the proof for $0 \leq t \leq T_{1} \leq T_{0}^{0}$ follows, by (3.6), that:

$\left(\left|\sigma^{\prime}(t)\right|+\|\sigma(t)\|\right)^{2} \leq \theta\|u-v\|_{Y_{T_{1}}}\|\sigma\|_{Y_{T_{1}}}, \quad 0 \leq t \leq T_{1}$

where $\theta=\frac{\alpha_{T_{0}}{ }^{2}}{\Gamma}\left(e^{2 \Gamma T_{1}}-1\right) \frac{4}{\min \left(1, m_{0}\right)}$. 
THWOREM 1. Given ${ }_{0} \subseteq \mathrm{D}\left(\mathrm{A}^{3 / 2}\right)$ and $u_{1} \in \mathrm{D}(\mathrm{A})$. Then there exists $T_{1}>0$ and a uniguc lunction $u:\left[0, T_{1}\right] \rightarrow D(A)$ such that:

$u \in 1::_{v}^{2}\left(\left[\mathrm{O}, \mathrm{T}_{1}\right] ; \mathrm{H}\right) \cap \mathrm{C}^{\mathrm{l}}\left(\left[\mathrm{O}, \mathrm{T}_{1}\right] ; \mathrm{H}\right) \cap \mathrm{C}\left(\left[\mathrm{O}, \mathrm{T}_{1}\right] ; \mathrm{V}\right)$

$u^{\prime}(t) \in v, \quad 0 \leq t \leq T_{1}$

$\frac{d}{d t}\left(u^{\prime}(t) \mid v\right)+\left(B\left(\|u(t)\|^{2}\right) A u(t) \mid v\right)=0, \quad \forall v \in H$

$u(0)=u_{0} \quad u^{\prime}(0)=u_{1}$

Moreover, there is $r=r(c)>0$ such that $\|u\|_{X_{T_{1}}} \leq r$.

PROOF : Let $T_{1}$ be definedin Lemma 3 .

We define $u \equiv 0, \quad u \in E_{T_{1}, C}$ and consider $u_{v+1}=s\left(u_{v}\right)$,

$v=0,1,2, \ldots$ where $u_{0}=u \stackrel{1}{=} 0$.

We note that $u_{\nu} \in \mathrm{X}_{\mathrm{T}_{1}} \subset \mathrm{Y}_{\mathrm{T}_{1}}, \forall \nu$. Furthermore, by Lemma 1 (§3), we have that $\left\|u_{v}\right\|_{\mathrm{X}_{\mathrm{T}_{1}}} \leq \mathrm{r}^{1} \forall \nu \cdot{ }^{1}$ Thus by Lemma 3 we obtain that $\left\|u_{\nu+1}-u_{\nu}\right\|_{Y_{T_{1}}} \leq \theta^{\nu}\left\|u_{1}\right\|_{X_{T_{1}}}$. Therefore for $\nu \geq$
$\left\|u_{\nu}-u_{\mu}\right\| \leq \frac{\theta^{\mu}}{1-\theta}\left\|u_{1}\right\|_{Y_{T_{1}}}$.

Which implies that there is $u \in \mathrm{Y}_{\mathrm{T}_{1}}$ such that:

$\lim _{\nu \rightarrow+\infty} u_{\nu}=u \quad$ in $\quad Y_{T_{1}}$

By Lenuma 2, (3.12) and $(2.5)$, we obtain that:

$\lim _{\nu \rightarrow+\infty} B\left(\left\|u_{\nu}(t)\right\|^{2}\right)=B\left(\|u(t)\|^{2}\right)$ in $\quad \mathcal{L}(v)$

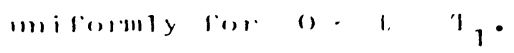

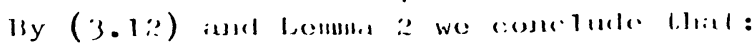

$u(t) \in u(\Lambda) \quad \forall t \in\left[0, \mathrm{~T}_{2}\right] \quad$ and $\left|\Lambda_{u}(\mathrm{t})\right| \leq r, \quad \mathrm{t} \in\left[0, \mathrm{r}_{1}\right]$.

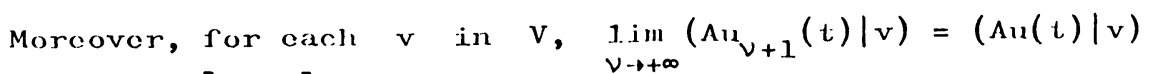
uniromly in $\left[0, T_{1}\right]$ hence

$\lim _{\nu \rightarrow+\infty}\left(\Lambda u_{v+1}(t) \mid v\right)=(\Lambda u(t) \mid v)$ wiformly in $\left[0, T_{1}\right] \quad \forall v \in \|$,

becausc $V$ is dense in JI.

Now, we have that

$$
\left(u_{v+1}^{\prime \prime}(t) \mid v\right)=-\left(B\left(\left\|u_{v}(t)\right\|^{2}\right) A u_{v+1}(t) \mid v\right), \quad \forall v \in 11
$$

consequently, by using (3.13) and (3.14) we obtain, that

$\lim _{v \rightarrow+\infty}\left(u_{v+1}^{\prime \prime}(t) \mid v\right)=-\left(B\left(\|u(t)\|^{2}\right) A u(t) \mid v\right), \quad \forall v \in H$ unirormly

Therefore, by $(3.12)$, then $u \in C_{\omega}^{2}\left(\left[0, T_{1}\right] ; H\right)$ and

$\frac{d}{d t}\left(u^{\prime}(t) \mid v\right)=-\left(B\left(\|u(t)\|^{2}\right) A u(t) \mid v\right), \quad t \in\left[0, T_{1}\right] \quad \forall v \in H$.

By Lemma 2 and (3.12) we obtain that $u^{\prime}(t) \in v \quad t \in\left[0, T_{2}\right]$ and $\left\|u^{\prime}(t)\right\| \leq r, \quad l \in\left[0, T_{2}\right]$.

It remains to prove uniqueness. We consider $u$ and $v$ satisfying the Theorem 1 . We note that $|A u(t)|+\|u(t)\|=r \quad \forall t \in\left[0, T_{1}\right]$ 
and $|A v(t)|+\|v(t)\| \leq r \quad \forall t \in\left[0, T_{1}\right]$ then if we consider $\sigma(t)=$ $=u(t)-v(t)$ and using a similar proof of Lemma 3 we obtain that $\|\sigma\|_{\mathrm{Y}_{\mathrm{T}_{1}}} \leq \theta\|\sigma\|_{\mathrm{Y}_{\mathrm{T}_{1}}}<\|\sigma\|_{\mathrm{Y}_{\mathrm{T}_{1}}}$ and therefore $\sigma(\mathrm{t})=0 \quad \forall t, t \in\left[0, \mathrm{~T}_{1}\right]$. ACKNOWLEDGEMENTS. This paper is dedicated to Proressor P.H. Rivera (in memoriam) friend and adviser. The author would like to thank Professor G.P. Menzala for his helpful suggestions.

\section{REFERENCES}

1. RIVERA, P.H. Existence of solutions of the equation $u_{t t}-M\left(x,|\nabla u|^{2}\right) \Delta u=F$ (in Spanish), Proc. 10 th Brazilian Seminar of Analysis (S.B.M.), Rio de Janeiro (1979), Brazil.

2. MENZALA, G.P. On classical solutions of a quasi-linear hyperbolic equations, Nonlinear Anal. 3 (1979), 613-627.

3. LIONS, J.L. On some questions in boundary value problems of Mathematical Physics, in: International Symposium on Continuum Mechanics and Partial Differential Equations, Rio de Janeiro 1977, North-Holland, 1978.

4. AROSIO, A., SPAGNOLO, S. Global solutions of the Cauchy problem for a nonlinear hyperbolic equation, Università di Pisa, Dipartamento di Matematica, Roma 1982.

5. EBIHARA, Y., MIRANDA, M., MEDEIROS, L.A. Local solutions ror a nonlinear degenerate hyperbolic equation, Nonlinear Anal. theory Appl. and Math. (to appear).

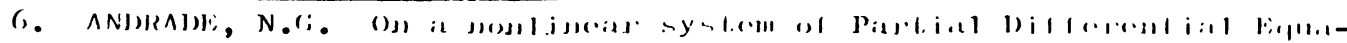

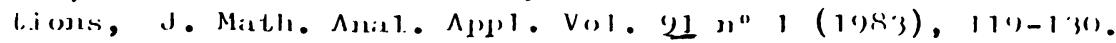

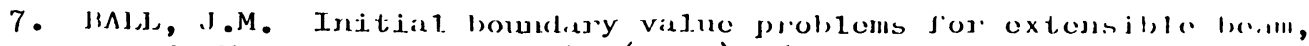

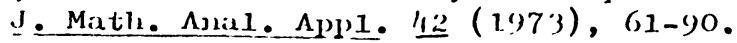

8. MENSTEIN, I.N. On a class of functional differential oumations (in Russian), ILv. Acal. Nal1k. SSSR, Math. 生 (1960), 1.7-:26.

9. DICKEY, R.W. The initial value proll.em for a nonlinoar semi inrinite strinc, Proc. Roy. Soc. 82 A (1978), 19-26.

10. GREENBERG, J.M., IIU, S.C. The initial value problem for a stretched strine, Quartely Appl. Math. (1980), 289-311.

11. MEDEIROS, L.A. On a new class of nonlinear wave equations, J. Math. Anal. and Appl. vol. 69 no 1 (1979), 252-262.

12. MENZALA, G.P. On global classical solutions of a nonlinear wave equation, Applicable Analysis 10 (1980), 179-195.

13. NISHIDA, T. A note on nonlinear vibrations of the elastic string, Mem. Fac. Enc. Kyoto Univ. 34 (1971), 329-341.

14. NISHIHARA, $K$. On a global solution of some quasilinear hyperbolic equation, Tokyo J. Math., vol. I, (2), 1984.

15. POHOZAEV, S.I. On a class of quasilinear hyperbolic equations, Math. USSR Sbornik 25, (1975), 145-158.

16. RIVERA, P.H. On local strong solutions of a nonlinear partial differential equation, Applicable Analysis 10 (1980), 93-104.

17. RIBEIRO, N.M. Sobre uma equação diferencial parcial não linear da física matemática, An. Acad. Bras. Cienc. (1981), 53 (2), 251-253.

18. YAMADA, Y. On a quasilinear wave equation, Suiken, Kokyuroku, 386, Kyoto Univ. (1980).

19. YAMAD.1, Y. On some quasilinear wave equations with dissipative term, Nagoya Univ. J., 87 (1982), 17-39.

20. GoldSTEIN, J. Time dependent hyperbolic equation, J. Functional Analysis 4, (1969), 31-49. 


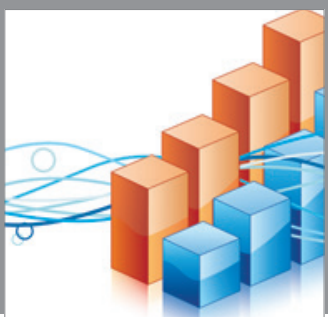

Advances in

Operations Research

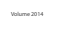

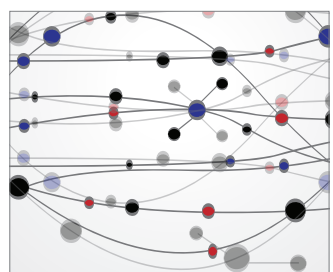

\section{The Scientific} World Journal
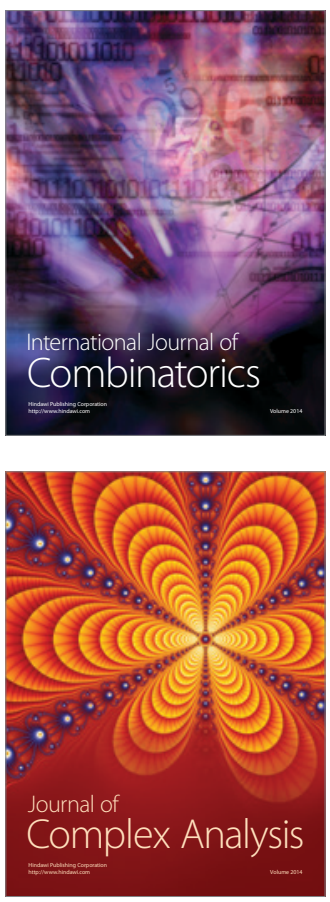

International Journal of

Mathematics and

Mathematical

Sciences
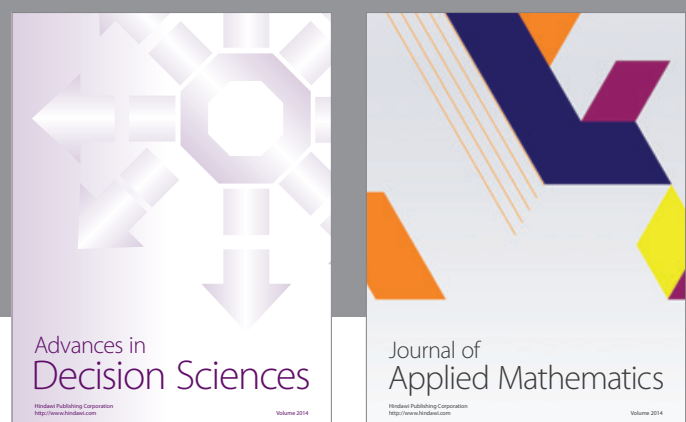

Journal of

Applied Mathematics
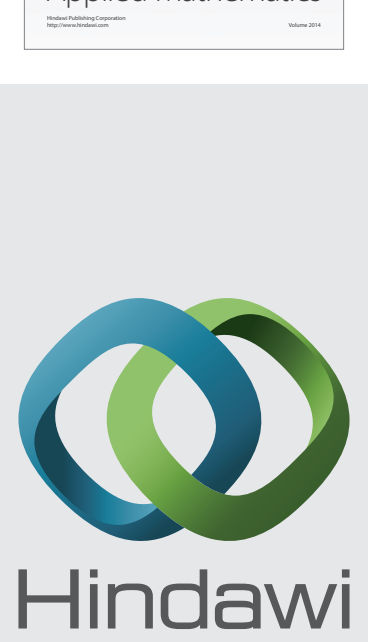

Submit your manuscripts at http://www.hindawi.com
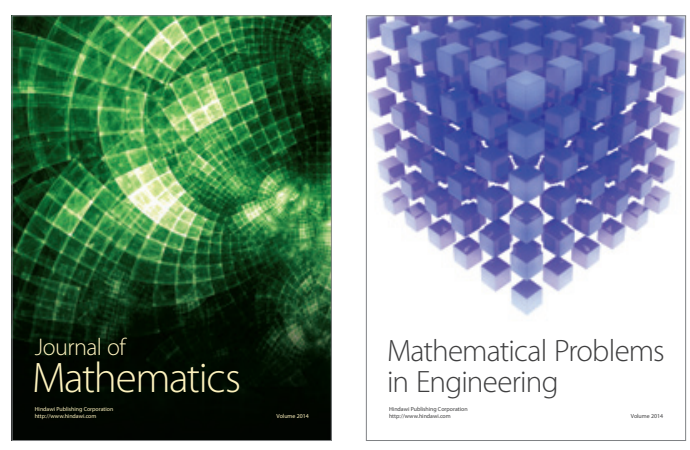

Mathematical Problems in Engineering
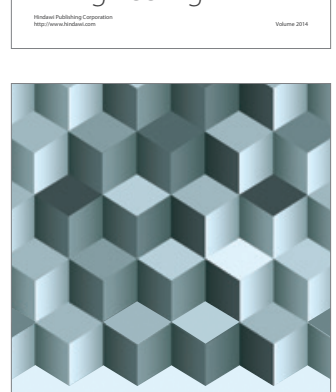

Journal of

Function Spaces
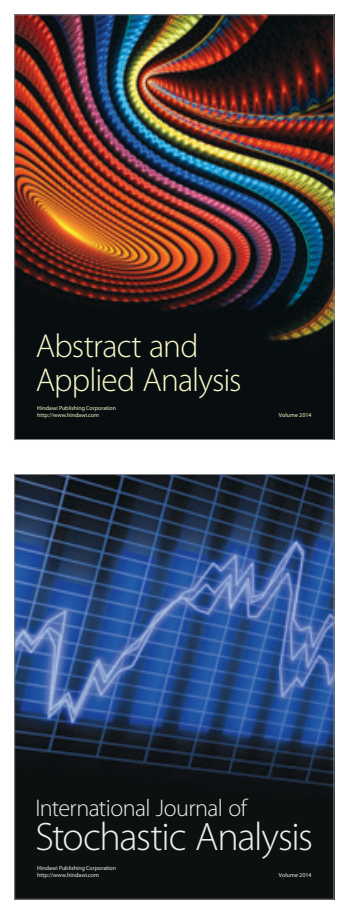

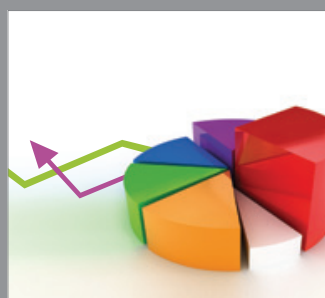

ournal of

Probability and Statistics

Promensencen
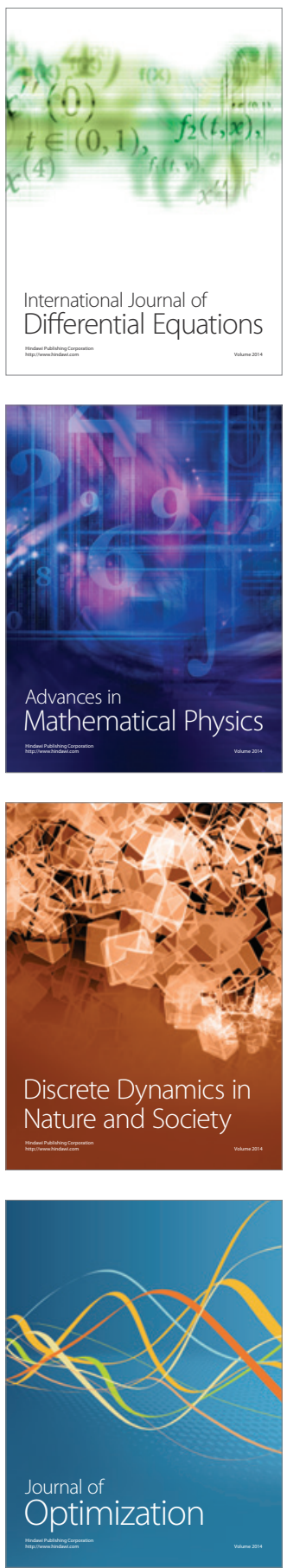